\title{
ADC, ACN E FONTES ORAIS: ALGUMAS REFLEXÕES SOBRE INTERDISCIPLINARIDADE E IDEOLOGIA
}

(ADC, ACN andoral sources: somereflectionson interdisciplinarity and ideologie)

\author{
Glauco Vaz Feijó ${ }^{1}$ \\ (Instituto Federal de Brasília - IFB)
}

\begin{abstract}
This article is the result of theoretical and methodological issues arising in the context of research on discourse representation of identities in oral narratives of Brazilian immigrants in Europe. Working with oral narratives led me to interdisciplinarity involving Oral History, Critical Discourse Analysis (CDA) and Critical Analysis of Narrative (ACN). From this methodological hybridity came the theoretical reflections on the central concepts of the disciplines with which I dialogue from the perspective of a cultural historian. Theoretical reflections focus on the critique on the conception of ideology adopted by the ADC. The presented critique is built upon conceptions of Cultural Studies and of ACN.
\end{abstract}

Keywords: Critical Discours Analysis; Critical Narrative Analysis; Oral History; interdisciplinarity; ideologie

\section{RESUMO}

Este artigo é resultado de reflexões teórico-metodológicas surgidas no contexto de uma pesquisa sobre representação discursiva de identidades em narrativas orais de imigrantes brasileiras/os na Europa. O trabalho com narrativas orais me levou à interdisciplinaridade envolvendo História Oral, Análise de Discurso Crítica (ADC) e Análise Crítica de Narrativa (ACN). Deste hibridismo metodológico vieram as reflexões teóricas sobre conceitos centrais das disciplinas com que dialogo a partir da perspectiva de um historiador da cultura. As reflexões teóricas se centram na crítica à concepção de ideologia adotada pela ADC. A crítica é construída com o apoio de concepções dos Estudos Culturais e da ACN.

Palavras Chave: Análise de Discurso Crítica; Análise Crítica de Narrativa; História Cultural; interdisciplinaridade; ideologia.

\section{Introdução}

Antes de começar, faz-se mister dizer que as reflexões teórico-metodológicas deste artigo não pairam no ar, erguendo-se a si mesmas pelos próprios cabelos, pelo contrário, elas são fruto de um trabalho de pesquisa concreto, atualmente em fase de conclusão, sobre representações

\footnotetext{
${ }^{1}$ Professor do Instituto Federal de Educação, Ciência e Tecnologia de Brasília (IFB) e Doutorando do Programa de Pós-Graduação em História da Universidade de Brasília (PPGHIS/UnB) em cotutela com o Instituto de Romanística da Friedrich-Schiller Universität Jena. Possui graduação em Ciências Sociais - Bacharelado (1997) e Licenciatura (1999) - pela Universidade Federal Fluminense e Diploma de Estudios Avanzados en Historia pela Universidad de Huelva, Espanha (revalidado como Mestrado em História pela Universidade Federal da Bahia). Foi Lehrbeauftragter (professor contratado) e Pesquisador Visitante no Instituto de Romanística da FriedrichSchiller-Universität Jena (Alemanha) e Professor Substituto do Departamento de História da Universidade Federal da Bahia. Tem experiência nas áreas de Educação, História e Estudos Culturais, atuando principalmente nos seguintes temas: estudos e encontros culturais; raça e racismo no Brasil.
} 
discursivas de identidades nacionais por meio de narrativas de trajetórias de vida de imigrantes brasileiros e brasileiras na Alemanha e em Portugal. Portanto, quando no artigo me remeto à “pesquisa”, é dessa pesquisa que estou falando e foi essa pesquisa que me levou às reflexões que passo a compartilhar.

\section{Aproximações metodológicas a partir dos estudos da linguagem}

Para começar, devo esclarecer que entendo multidisciplinaridade, interdisciplinaridade e transdisciplinaridade de forma muito próxima ao que van Leeuwen (2005) considera serem "três modelos de interdisciplinaridade": o modelo centralista; o modelo pluralista e o modelo integracionista, respectivamente. Tomo então para multidisciplinaridade, interdisciplinaridade e transdisciplinariade as definições elaboradas por van Leeuwen para cada um de seus "modelos de interdisciplinaridade":

Um modelo centralista de interdisciplinaridade é essencialmente um modelo de relação entre diferentes disciplinas autônomas. Apesar de se situar entre outras disciplinas, cada disciplina se vê como o centro do universo do conhecimento e, a partir deste centro, traça suas relações com outras disciplinas (...). Em modelos pluralistas, tópicos e problemas são centrais e reconhece-se que estes podem legitimamente pertencer a um número de diferentes disciplinas. $\mathrm{O}$ modelo pluralista procura antes juntar tais disciplinas como parceiras iguais, que incorporar elementos de outras disciplinas em uma disciplina 'centralista'. No entanto, as disciplinas permanecem autônomas e auto-suficientes na forma como elas operam, suas identidades e valores não são fundamentalmente afetados (...). O modelo integracionista se concentra mais em problemas do que em métodos (...). Mas aqui é reconhecido que nenhuma disciplina pode resolver satisfatoriamente qualquer problema sozinha (...). Trata-se de uma grande mudança na maneira como funcionam as disciplinas e, às vezes, esse modelo pode ser visto como uma ameaça ao status quo (2005: 4$6)^{2}$.

Durante a pesquisa, o trabalho simultâneo com História Oral, Análise de Discurso Crítica e Análise Crítica de Narrativa, conduziu-me ao desafio de tentar promover o diálogo entre as disciplinas História, Linguística e Narratologia.

Partindo da definição de Marc Bloch, que nos apresenta a história como o estudo do ser humano no tempo, lembro, com Paul Ricouer (1994), que a narrativa é o que torna humano o tempo e também, com Thomas Mann, que a narrativa é o conteúdo do tempo. Num silogismo fácil, creio então poder argumentar que, se o tempo é central nos estudos da história, esse é obviamente o tempo humano e nenhum outro, sendo assim, se o conteúdo do tempo é preenchido pelas narrativas, que ao preenchê-lo também o humaniza, a narrativa torna-se objeto

${ }^{2}$ Todas as citações de textos em língua estrangeiras foram por mim traduzidas. 
de interesse primordial do historiador. Além disso, ao ter como fontes de pesquisa narrativas geradas por entrevista de história oral, atendi de pronto ao apelo da historiadora Verena Alberti (2003) quando argumenta que:

Um acontecimento ou uma situação vivida pelo entrevistado não pode ser transmitido a outrem sem que seja narrado. Isso significa que ele se constitui (no sentido de tornar-se algo) no momento mesmo da entrevista. Ao contar suas experiências, o entrevistado transforma aquilo que foi vivenciado em linguagem, selecionando e organizando os acontecimentos de acordo com determinado sentido. Esse trabalho da linguagem em cristalizar imagens que remetem a, e que significam novamente a experiência é comum a todas as narrativas (...). Mas talvez não tenhamos dado ainda a devida atenção para esse trabalho da linguagem nas chamadas fontes orais". (Alberti, 2003: 1)

Assim, optei por, durante a interpretação das fontes orais de minha pesquisa, dedicar uma atenção especial ao trabalho com a linguagem. Para isso, dispus das ferramentas metodológicas que oferecem a Análise de Discurso Crítica e a Análise Crítica de Narrativas.

Narrativas, discursos e identidades são as ideias que chamo de fundantes da pesquisa. Ligadas a essas ideias fundantes, metodologias, que chamo de estruturantes, se impuseram de forma desafiadora. Quer dizer, a escolha ontológica das ideias fundantes, aliada à opção epistemológica pelo trabalho com entrevistas, trouxe consigo, a reboque, as metodologias estruturantes, quais sejam: História Oral, Análise de Narrativas e Análise de Discurso Crítica. Sendo que:

Narrativas não são vistas como uma forma meramente literária, mas como uma forma fundamental de organizar a experiência humana e como uma ferramenta para a construção de modelos da realidade (...). Narrativas, portanto, permitemaos seres humanos entrar em acordo com a temporalidade da sua existência (...). Ao contar histórias,ordenamos eventos caóticos, estruturando experiências heterogêneas vividas(Neumann et al., 2008: 4-5).

Foi o diálogo necessário entre essa perspectiva de narrativa, fundamentalmente baseada na experiência humana do tempo, característica maior do conhecimento histórico, e o uso da história oral como prática metodológica interdisciplinar que me levaram à busca de uma aproximação indispensável com a narratologia, nomeadamente a narratologia desenvolvida a partir do narrative turn dos anos 1990 (Bamberg, 2009).

Depois do chamado narrative turn, a narratologia, incluído aí o estudo das "narrativas orais", tornou-se um dos campos mais propícios para o diálogo entre diferentes áreas que se propõem a romper fronteiras dentro de um campo maior que são os Estudos Culturais. Para Vera e Ansgar Nünning, a abrangência dos estudos de narrativa hoje é uma de suas características mais notáveis: 
Muitas das novas abordagens reimportam para o antes tão claramente definido campo da narratologia exatamente aquelas categorias que o paradigma da cientificidade precisa, tão empenhado em atingir exatidão, antes, conscientemente, esvanecera: as dimensões da história e da variabilidade histórica das formas narrativas, estética, ética, ideologia, interpretação e, finalmente, a dimensão sócio-cultural, que inclui categorias como raça, classe e gênero (Nünning; Nünning, 2009:20)

Assim percebo a construção dos resultados da pesquisa, ela mesma uma narrativa, enraizada na História, mas se apoiando também em outros troncos, sobretudo, na linguística, por meio da ADC e na nova narratologia - fortalecida após o narrative turn - buscando a sustentação mais segura possível.

Em obra influente sobre o que chama de teoria da história oral, Lynn Abrams defende que:

Fontes de história oral também são fontes narrativas, historiadores devem então usar as teorias vindas da interpretação de textos de literatura e de folclore, e aquelas vindas da linguística e da psicologia(...). O ponto importante aqui é que, como os historiadores usando história oral, precisamos estar atentos para a natureza essencialmente narrativa das fontes orais e reconhecer que precisamos empregar as ferramentas dos teóricos da narrativa para desempacotar nossas fontes. (Abrams, 2010: 18-21)

Creio, então, que as metodologias empregadas, ainda que múltiplas, ou híbridas, se concatenam em um todo coerente, pois surgem umas das outras, sem que se possa dizer com muita precisão onde se encontram seus limites. A opção que fiz, parece-me, foi a de trabalhar com entrevistas e ter a história oral como metodologia de trabalho, daí derivaram as demais metodologias, das exigências contemporâneas que o uso da história oral como metodologia aberta ao diálogo permissivamente nos impõe.

A interdisciplinaridade metodológica que proponho deriva das exigências impostas pelo trabalho com narrativas orais e se constrói sobre a proposta de interpretação de narrativas desenvolvida por Motta (2013). Motta propõe uma interpretação crítica de narrativa por meio da abordagem da narrativa em três planos concomitantes e interseccionados. O autor nomeia seus planos de abordagem como "plano da estória", que serviria para a interpretação das estratégias narrativas; "plano da expressão", no qual se concentrariam as interpretações textuais e discursivas; e "plano da metanarrativa", que seria o "plano da estrutura profunda, relativamente mais abstrato e evasivo, que evoca imaginários culturais” (Motta, 2013: 138). Eu, em minha apropriação do modelo de Motta para a interpretação de fontes de história oral, tomo a liberdade de alterar os nomes, trabalhando com "plano da história" e "plano do discurso", mantendo a denominação "plano da metanarrativa". 
Com a primeira alteração, ao mesmo tempo em que evito entrar na discussão sobre as diferenças ou não entre narrativas ficcionais e narrativas fáticas, não deixo de tomar posição sobre a existência e importância de diferenças entre elas, sendo que no meu trabalho trato de história, de narrativas fáticas, e não de "estória", de narrativas ficcionais. Cabe, contudo, deixar claro que, embora as narrativas interpretadas se relacionem a fatos históricos maiores, que lhes são exteriores, os fatos históricos interpretados em minha abordagem de história oral são as próprias narrativas e não outros, externos e, pretensamente, mais grandiosos ou grandiloquentes.

Com a segunda alteração, ao usar "plano do texto" em vez de "plano da expressão", quero apenas dar ênfase às estratégias discursivas que são os aspectos mais relevantes e reveladores deste plano, também para Motta, que descreve o plano da expressão como sendo "o plano da linguagem, o plano da superfície do texto (...). Plano do discurso propriamente dito" (Motta, 2013: 136). Julgo apenas então mais adequado chamar a coisa pelo nome.

No "plano da história", proponho reconstruir as narrativas interpretadas para descobrir seus enredos e, portanto, "sua inteligibilidade como totalidade" (Motta, 2013: 140). O enredo se constrói por sequências-tipo, episódios, estratégias argumentativas, atores e seus conflitos, que, ao serem desvendados e interpretados, ajudam-nos a entender o contexto histórico-cultural que permite a construção da narrativa, nos ajudam a vislumbrar o contexto pré-narrativo, que é o que de fato nos interessa em uma interpretação de narrativas pós-estruturalista.

Com a observação das estratégias argumentativas e dos atores da narrativa, a atenção se centra no "plano da expressão" (Motta, 2013), ou "plano do texto", como eu prefiro chamá-lo, onde os usos da linguagem são reveladores da história, da cultura e das relações sociais que embasam as narrativas interpretadas. Em vez de seguir única e fielmente com as ferramentas da ACN inicialmente utilizadas, ao escolher trabalhar com atores em vez de personagens, integro transdisciplinarmente a ACD à interpretação proposta, partindo da interpretação da representação de atores sociais proposta por van Leeuwen (2008), incluindo aí também a interpretação dos elementos de intertextualidade e chegando à interpretação de categorias como os significados acionais, representacionais e identificacionais proposta por Fairclough (2003).

Envolvendo e cortando os dois planos anteriores em todos os tempos e sentidos, está o "plano da metanarrativa", plano por excelência de atuação do/a historiador/a cultural. Esse plano deve permear toda a interpretação, pois tanto a $\mathrm{ACN}$, predominante no plano da história, quanto a ADC, predominante no plano do texto, ambas nos remetem a questões históricoculturais anteriores à narrativa interpretada, nos remetem a categorias ideológicas sobre as quais 
as narrativas se constroem. Enredos narrativos e estratégias de linguagem são manifestações de conflitos profundos enraizados na cultura e latentes no discurso. Tanto ADC quanto ACN nos permitem um acesso a estes conflitos profundos por meio do texto narrado. No caso da minha pesquisa, ADC e ACN permitem-me interpretar a (re)construção de identidades nacionais fundadas em um processo histórico conflituoso e ainda em curso da formação de identidades nacionais brasileiras.

\section{Reflexões teóricas a partir dos Estudos da Cultura}

A ideia de discurso que utilizo, tomo-a emprestada da Análise de Discurso Crítica (ADC), buscando me apropriar de ideias e instrumentos metodológicos de distintas escolas, que, embora não coincidentes e em alguns momentos conflitantes, guardam ainda afinidades entre si. Uma ideia de discurso que creio não desagradar nem a austríacos/as, nem a holandeses/as, nem a ingleses/as é a proposta por Chouliaraki e Fairclough:

Análise do Discurso Crítica (...) começa a partir da percepção do discurso (língua, mas também outras formas de semiose, como imagens visuais) como um elemento das práticas sociais, que molda outros elementos, bem como é moldado por eles. As questões sociais são, portanto, em parte, questões discursivas (...). [A] análise linguística e semiótica cuidadosa de textos (...) e de interações (por exemplo, conversas ou entrevistas), tem, portanto, um papel a desempenhar na análise social (Chouliaraki; Fariclough, 2009:vii)

Usaremos o termo 'discurso' para nos referir a elementos semióticos de práticas sociais. Discurso inclui, portanto, língua, (...) comunicação não-verbal (...) e imagens visuais (...). O conceito de discurso pode ser entendido como uma perspectiva particular sobre as várias formas de semiose - como momentos de práticas sociais em sua articulação com outros momentos nãodiscursivos (Chouliaraki; Fariclough, 2009: 38)

Nesse ponto, acho oportuno esclarecer que, embora me aproprie da ideia de discurso de Chouliaraki e Fairclough, não me proponho a utilizar ostensivamente a ADC como teoria, assim como o fazem esse autor e autora na obra citada. Limito-me a utilizar a ADC como metodologia, aproximando-me mais, creio, da posição de van Leeuwen, quando, argumentando sobre um caso específico, propõe que:

Como analistas de discurso, só podemos reconhecê-los [os usos de expressões com uma dimensão avaliativa] com base em nosso conhecimento cultural do senso comum. A utilidade da análise do discurso linguístico para neste ponto, e a pesquisa histórico-discursiva tem que entrar em cena. Só o historiador social e cultural pode explicar o status moral dessas expressões, levando-as de volta aos discursos morais que lhes estão subjacentes, desfazendo assim a 'amnésiada gênese' (Bourdieu) que nos permite tratar tais 'avaliações morais' 
como valores do senso comum que não precisam ser explicitados (van Leeuwen, 2005: 12)

Aqui a ADC aparece como metodologia, como a utilizo. Uma metodologia extremamente profícua se bem utilizada em um campo interdisciplinar no qual historiadores da cultura poderiam dar contribuições significativas, algo que parece ainda não ocorrer com muita frequência. Cabe ainda frisar ainda que, embora trabalhe com diferentes abordagens da ADC, faço-o não por concordar com todas as suas perspectivas teóricas, mas por achar mais profícua uma aproximação complementar, colhendo de cada uma aquilo que se aproxima de minhas próprias crenças e valores e excluindo perspectivas das quais discordo, apoiando-me para isso nas próprias autocríticas internas à ADC.

Assim como não trabalho com a proposta de Chouliaraki e Fairclough de utilização da ADC como teoria, tampouco parto de uma premissa fundante para muitos expoentes da ADC, como para o próprio Fairclough, de que a as teorias críticas devem ter por objetivo desvendar mecanismos de dominação, desmitificando os discursos e decifrando as ideologias que frequentemente impedem que sujeitos percebam que são enganados a respeito de suas próprias necessidades e interesses. Assim compreendo, por exemplo, as palavras de Wodak ao comentar o papel das teorias críticas, entre as quais inclui a ADC:

Ainda que adotem conceitos diferentes de ideologia, as teorias críticas pretendem despertar nos agentes a consciência de que, com frequiência, eles são enganados a respeito de suas próprias necessidades e interesses. (...) Um dos objetivos da ADC é 'desmistificar' os discursos decifrando as ideologias. (Wodak, 2004:236)

Assim como Motta (2013) - que faz crítica muito semelhante a Teun van Dijk, apesar de trabalhar com várias outras contribuições deste analista crítico do discurso -, considero que esse posicionamento da ADC está muito atrelado à sociologia crítica da Escola de Frankfurt e às suas teorias sobre o controle do poder e o exercício da dominação. Considero que esta posição está também muito atrelada à dificuldade que as teorias críticas, em maior ou menor medida influenciadas pelo marxismo, têm para superar os debates sobre as diferentes acepções em que o próprio Marx utiliza o termo ideologia, na maior parte das vezes empregando-o, de fato, para nomear as ideias burguesas intencionalmente manejadas para "mistificar" o mundo aos homens e mulheres comuns, cabendo então ao intelectual, único ser capaz de enxergar por entre as névoas da ideologia, salvar seus semelhantes.

Ainda com Motta, reconheço a importância da teoria crítica dos frankfurtianos, mas não deixo de me incomodar com seu iluminismo exacerbado, comungo com este autor uma visão que creio gramsciana das correlações de forças. Para Motta: 
O todo social é um espaço assimétrico de confrontos e contradições permanentes (...) o nível discursivo, cultural e ideológico é um entre outros níveis de conflito de poder. A luta ideológica é permanente, enquanto houver assimetria social. Neste sentido, cada grupo conforma representações próprias opondo-as às outras, age estrategicamente, avança e recua politicamente, conquista e cede terreno. A força política e simbólica do grupo hegemônico jamais penetra todos os recônditos da sociedade nem impede manifestações culturais contra-hegemônicas. Elas podem ou não se consolidar como representações tangíveis. A consolidação de uma ideologia ou representação tangível e estável depende, em cada momento, da correlação de forças (poder) específica (Motta, 2013: 22-23)

Também entendo as "formações discursivas" à moda gramsciana como processos históricos de correlações de forças, processos conduzidos por grupos humanos em constante luta pela hegemonia, e essa luta se dá também ao nível discursivo. Não tenho, pois, intenção de desmistificar as narrativas de meus/minhas colaboradores/as, pois não as ouço como mitos, pelo menos não no sentido de deturpação do real, que embasa a necessidade de desmistificação. Se em algum momento aponto para a possibilidade de enxergar as narrativas como mitos, é em um processo histórico e criativo de construção do presente que estou pensando. O que proponho é desvendar um pouco o imaginário desses/as imigrantes brasileiros/as por meio das narrativas de suas trajetórias de vida, sendo que o imaginário não é tomado como o oposto do real, mas como parte dialógica deste real (Boia, 1998), como fruto da imaginação criativa que nos torna humanos/as e que é parte essencial de nossa interação com o mundo (Castoriadis, 1997).

A ideia de ideologia em grande parte empregada na ADC é ainda caudatária das reflexões althusserianas dos anos 1970, que, embora tenham dado uma grande contribuição para o rompimento com uma ideia anterior (que ainda persiste entre nós) de ideologia como falsificação do real , continua deixando em segundo plano as contradições entre as diferentes ideologias em embate nas relações sociais de reprodução e transformação social, conforme instigante interpretação de Hall sobre o problema da ideia de ideologia desenhada por Althusser em seu pequeno clássico Aparelhos ideológicos de Estado:

A ideologia nesse ensaio parece ser, principalmente, aquela da classe dominante. Se existe uma ideologia das classes dominadas, esta parece estar perfeitamente adaptada aos interesses e funções da classe dominante no modo capitalista de produção. Neste ponto, o estruturalismo althusseriano torna-se vulnerável à acusação, que tem sido dirigida contra ele, de um sorrateiro funcionalismo marxista. A ideologia parece exercer a função que dela se demanda (qual seja, reproduzir a dominância da ideologia dominante), exercêla com eficácia e continuar assim, sem encontrar quaisquer 'contra-tendências' (...). Quando se questiona sobre o campo contraditório da ideologia, sobre como a ideologia das classes dominadas é produzida e reproduzida, sobre as ideologias de resistência, de exclusão, de desvio etc., não há respostas nesse ensaio. Tampouco há uma explicação para o fato de a ideologia, tão 
efetivamente costurada à formação social na narrativa de Althusser, produzir seu oposto ou sua contradição (Hall, 2003: 172-173).

Creio que a ideia de ideologia predominante entre os principais autores da ADC não foge a esse aspecto da ideologia althusseriana, o que os leva por caminhos e propostas diferentes das que sigo em minha pesquisa. Mas, a mesma ideia althusseriana de ideologia, presente no mesmo pequeno e problemático clássico Aparelhos ideológicos de Estado, tem a virtude de nos apresentar a materialidade da ideologia, ao encará-la como práticas sociais e não como processos puramente mentais. A materialidade da ideologia como prática social se dá talvez principalmente, mas não exclusivamente, por meio da linguagem, quer dizer, discursivamente, e é nesse ponto, bastante explorado pela ADC, que suas diferentes Escolas vêm ao encontro e ao auxílio de minha proposta, nesse ponto somos iguais apesar de nossas diferenças.

Viviane Ramalho e Viviane Resende são duas autoras vinculadas aos estudos sobre linguagem e sociedade que vêm se empenhando bastante na difusão da ADC no contexto brasileiro (Resende, 2009; Resende e Ramalho, 2009; Ramalho e Resende, 2011). As duas autoras dão bastante ênfase tanto ao caráter interdisciplinar da $\mathrm{ADC}$, quanto à abertura da $\mathrm{ADC}$ para o debate. Ramalho e Resende caracterizam a ADC como "heterogênea, instável e aberta" (Ramalho; Resende, 2011: 18), sendo essas características que impulsionam "a ADC para um aperfeiçoamento constante" (2011:19). Para elas:

A ADC caracteriza-se por uma heterogeneidade de abordagens que estabelecem diferentes relações interdisciplinares com diferentes disciplinas das ciências sociais. Essas relações interdisciplinares foram fundamentais par ao surgimento da ADC e são fundamentais par seus avanços (Ramalho; Resende, 2011: 20)

Essa busca pelo diálogo interdisciplinar, tanto no plano metodológico quanto no plano teórico, tem marcado a importante empreitada de difusão da ADC no Brasil conduzida por essas pesquisadoras. Sinto-me então convidado ao diálogo e volto-me para a ideia de ideologia presente no trabalho de difusão da ADC de Ramalho e Resende.

No mesmo livro logo acima citado, as analistas afirmam, com razão, que "a ADC mantém um diálogo fundamental com a abordagem crítica de ideologia de Thompson" e é por meio desta leitura particular da ideologia feita por Thompson (1990) que Ramalho e Resende afirmam que "na ADC 'ideologia’ é um conceito inerentemente negativo" (Ramalho; Resende, 2011: 25). Apesar da afirmação categórica, aparentemente fechada ao diálogo, o conjunto da obra das autoras me dá a certeza de que mesmo nesse ponto que lhes parece fundamental, como em quase todos os outros, os ouvidos para vozes discordantes estão abertos. 
Partindo também da necessidade do "desvelamento de ideologias", Ramalho e Resende dirigem brevemente seus argumentos para um embate entre a "ciência", representada pela ADC, e o senso comum, reino das ideologias, esquecendo-se de outro autor que também as embasa e que há quase três décadas vem propondo a necessidade de uma nova epistemologia que supere o embate com o senso comum (Santos 2011). Mais do que "romper o senso comum" (Ramalho e Resende, 2011), creio poder ser mais profícuo o caminho ainda tão pouco trilhado de lutar pelo senso comum, em outras palavras, lutar pela hegemonia, lembrando com Gramsci que "la realización de un aparato hegemónico, em cuanto que crea un nuevo terreno ideológico, determina una reforma de las conciencias y de los métodos de conocimiento" (Gramsci, 2001:146).

Ramalho e Resende, ao que parece, apoiam-se na interpretação de Fairclough sobre a concepção de hegemonia em Gramsci. Contudo, aparentemente, se esquecendo de que a ideologia desempenha um papel fundamental no desenvolvimento gramsciano da concepção de hegemonia, originalmente leninista (Gruppi, 1972). Se em Lênin a hegemonia passa sobretudo pela conquista do Estado, ganhando relevância então a força, em Gramsci a hegemonia passa fundamentalmente pela conquista da Sociedade Civil rumo ao Estado Integral (Portelli, 1990), nessa "guerra de posições" os embates ideológicos ganham centralidade e a construção de uma ideologia das classes subalternas é uma estratégia sine qua non para a alteração das relações hegemônicas.

Embora mencionada pelas autoras, a discussão em torno do conceito de hegemonia (e necessariamente de ideologia) em Gramsci cede terreno para a concepção inerentemente negativa de Thompson. Ramalho e Resende elaboram um quadro resumo bastante completo e esclarecedor das características da ideologia discutidas por Thompson (Ramalho e Resende, 2011: 27-28). Embora não caiba nos limites deste artigo uma discussão detalhada de cada um dos cinco modos de operação da ideologia e de suas respectivas treze estratégias de construção simbólica, podemos nutrir o debate em torno de ao menos dois desses modos e de suas estratégias. Tomemos, por exemplo, o primeiro e o último dos modos de operação da ideologia listados pelas autoras, quais sejam, "legitimação" e "reificação", e suas respectivas estratégias de construção simbólica: racionalização, universalização e narrativização, para o modo de operação "legitimação"; e naturalização, eternalização e nominalização, para o modo de operação "reificação".

As estratégias do modo de operação "legitimação" são assim definidas pelas autoras: 
A estratégia de racionalização consiste em utilizar fundamentos racionais, apelos à legalidade, a bases jurídicas para legitimar relações assimétricas de poder. A universalização, por sua vez, diz respeito à estratégia de difundir, disseminar representações particulares como se fossem de interesse geral, universal. A narrativização, por fim, consiste na estratégia de reproduzir histórias, no curso de nossas vidas cotidianas, que legitimam relações de dominação com base em tradições, costumes, dotes carismáticos, prestígio de pessoas particulares (Ramalho; Resende, 2011: 28-29)

O modo de operação "reificação" tem suas estratégias definidas da seguinte forma:

São quatro as estratégias ligadas a esse modo: a naturalização, pela qual criações sociais e históricas são representadas como acontecimentos do mundo natural; a eternalização, estratégia pela qual fenômenos sócio-históricos são representados como permanentes; a nominalização e a passivação, em que eventos e processos sociais são destituídos de ação humana, pelo apagamento de atores e ações (Ramalho; Resende, 2011: 30)

Para dialogar com tais estratégias e modos de operação, proponho abordá-las "a contrapelo", por meio de uma ideia que eu considero ideológica, mas que dentro de uma concepção exclusivamente negativa de ideologia não poderia sê-lo. Para tanto, faz-se necessário excluir as expressões de valor negativo presentes nas definições das autoras, substituindo "relações assimétricas de poder" e "relações de dominação" por "relações sociais".

Tomemos como exemplo, nessa estratégia a contrapelo, o conceito de Direitos Humanos (DH) e o analisemos dentro do quadro baseado em Thompson. Mesmo sem nos esmerarmos em detalhes e argumentos salta aos olhos que os DH utilizam as estratégias discursivas apontadas nas citações acima, algumas de forma clara e direta outras de forma mais sútil. Parece-me claro que o apelo à legalidade e à universalização são estratégias fundamentais na luta dos ativistas pelos DH por uma nova hegemonia, assim como me parecem óbvias as estratégias de naturalização e de eternização. Sobre a narrativização e a nominalização e passivação, embora não sejam estratégias, tão óbvias e talvez não tão cotidianas, não deixam de ser fundamentais para a luta. A narrativização desempenha um grande papel na luta pelos DH, por exemplo, por meio dos grandes líderes e mártires que servem de modelo e inspiração na continuidade da luta por parte de novas gerações. Quantas jovens e quantos jovens não se engajam na luta pelos DH ao ouvirem pela primeira vez o discurso que começa com "I have a dream" e continuam deixando correr dos olhos uma ou duas lágrimas a cada vez que voltam o escutá-lo? Provavelmente, a nominalização e a passivação não são as estratégias mais cotidianas nas lutas pelo DH, justamente pelo papel relevante que desempenha a narrativização, mas isso não significa que elas não sejam usadas. O são, por exemplo, na evocação das narrativas sobre da "Declaração dos Direitos Humanos", ou das anteriores "Declaração dos 
Direitos do Homem e do Cidadão" e a "Declaração de Independência Norte-Americana" (Hunt, 2009), que "foram reconhecidas", "foram elaboradas", "foram celebradas", quase sempre sem menção ao contexto, aos atores e interesses em disputas nessas elaborações, reconhecimentos e celebrações. Neste caso, a nominalização/passivação pode ser entendida como uma estratégia secundária usada para alcançar a estratégia central da universalização.

Seriam os DH então lógicos, naturais, universais e eternos? Obviamente que não. Os DH são, como sabemos, uma construção social, cultural e histórica; são invenções (Hunt, 2009) em constante processo de mutação, pois estão inseridos no cerne da luta hegemônica. Seriam os DH então uma ideologia? Sim. Seriam eles então algo inerentemente negativo? Não. Certamente não para quem “has a dream”, mas provavelmente sim, para quem não sonha com um mundo de horizontalidades e acredita na justiça das verticalidades. Caberia então relativizar os DH, pois eles não carregam consigo a verdade? A resposta mais simples para isso foi dada em 1969 por Norberto Bobbio (1992) e é um redondo não. Os direitos humanos são fundamento, e fundamentos não se discutem, partimos deste e de outros fundamentos para a luta por uma nova hegemonia e não nos interessa desvelar a verdade por trás dos Direitos Humanos, mas sim lutar por eles e lutar por sua apropriação, para que não sejam usados com instrumentos de opressão em vez de instrumentos de libertação. Conforme Hunt:

Os direitos humanos só se tornam significativos quando ganham conteúdo político. Não são os direitos de humanos num estado de natureza: são os direitos de humanos em sociedade. Não são apenas direitos humanos em oposição aos direitos divinos, ou direitos humanos em oposição aos direitos dos animais: são direitos de humanos vis-à-vis uns aos outros. São, portanto, direitos garantidos em um mundo secular (...) e são direitos que requerem uma participação ativa daqueles que o detêm. (Hunt, 2009: 19)

A inversão como artifício para revelar valores positivos usando um quadro delimitado para o desvelamento de ideologias inerentemente negativas serve ao argumento aqui defendido de que ideologias são combatidas com ideologias, pois na luta pela hegemonia, pelo consenso, são elas os elementos centrais. Há que se combater as ideologias negativas, obviamente, e nesse combate as ideologias positivas são as armas a serem usadas. Restringir a ideologia a algo inerentemente negativo é em si mesmo uma ideologia que naturaliza "os bons sentimentos" atribuídos aos seres humanos, como se todos os posicionamentos direcionados à emancipação dos seres humanos e para a supressão das relações de dominação fossem "verdadeiros", não precisando serem "desvelados". Se assim o fosse, não haveria ideologias, mas elas existem e ninguém está imune a elas, elas fazem parte da construção humana do mundo e não há nada de neutro nesta concepção. Não temos como nos despir das ideologias, nem devemos nos despir 
das ideologias. Temos que nos servir delas, que construir um aparato moral e político na luta por uma hegemonia que "naturalize" (também discursivamente) as relações de solidariedade e comunhão. Insistir na negação da ideologia em nome da "ciência" e contra o senso comum é um equívoco que vem sendo cometido menos à direita do que à esquerda, quase sempre, com a melhor das intenções. Cabendo, para interromper por aqui o diálogo, recordar o belíssimo alerta de E.P. Thompson em sua crítica ferina, por vezes grosseira, ao marxismo althusseriano:

Mais uma vez os intelectuais - um grupo escolhido entre eles - receberam a tarefa de iluminar o povo. Não há traço mais característico dos marxismos ocidentais, nem mais revelador de suas premissas profundamente antidemocráticas (...). É porém uma triste premissa para a teoria socialista (todos os homens e mulheres, exceto nós, são originalmente estúpidos) e destinada a levar a conclusões pessimistas ou autoritárias." (Thompson, 1991: 205)

Concordo com Gouveia(2003) quando ele propõe que o crescimento da ADC está claramente relacionado à crise do modelo científico racionalista vigente desde as últimas três décadas do século passado e exposta com toda clareza por autores como Boaventura de Sousa Santos(2011). Contudo, devo dizer que enxergo por trás da proposta desmistificadora da ADC resquícios das pretensões iluministas que acalentaram o mesmo modelo científico, de cuja crítica a ADC é caudatária. Mas vejo na ADC também o movimento constante da autocrítica, o que certamente potencializa a sua vontade de engajamento e de contribuição para a transformação social, dificultando que sua própria sobrevivência e preponderância acadêmica se tornem, em última instância, seu maior objetivo. Como projeto político, creio que talvez possa ser mais frutífero à ADC a busca pela hegemonia, que passa pela assunção das ideologias, em vez da busca pela "verdade".

O exercício da crítica serve, para mim, como reflexão sobre as armadilhas que a luta contra-hegemônica nos impõem e como pode ser difícil nos desvencilharmos de todas elas. Mas a ADC tem potencial para isso, pois se consolida como um projeto contra-hegemônico consistente e se lanço mão dela como uma das metodologias centrais em minha pesquisa é porque concordo com Fairclough ao encarar fenômenos sociais [e culturais] com sendo parcialmente discursivos (2003) e porque a vejo como uma excelente metodologia de interpretação das manifestações discursivas desses fenômenos. Além disso, quero tentar ser justo ao reconhecer que tanto Fairclough quanto Wodak deixam transparecer em vários textos que a abordagem que propõem é apenas uma entre outras. Ao defender-se da crítica de Paul Chilton (2005) sobre uma abordagem que se limitaria a explorar os aspectos de dominação e 
conservação da ideologia, esquecendo suas possibilidades de resistência e mudança, Fairclough argumenta que:

Devemos distinguir no entanto entre as questões e problemas a que não cheguei, porque outros me pareciam mais urgentes ou mais interessantes ou simplesmente porque a vida é curta (...). Um exemplo para o primeiro é a relativa ênfase sobre o funcionamento do poder, e não sobre o funcionamento da recepção, reação e resistência ao poder - sublinho relativa porque os últimos aspectos não foram totalmente negligenciados (...). Esta tem sido uma tendência no meu trabalho, talvez em parte por causa do tipo de política de esquerda que eu estava envolvido com na década de 1970 (Fairclough, 2009: 183)

Também Reisigl e Wodak, embora trabalhem claramente com a ideia da ideologia totalizadora e mistificadora, reconhecem em várias passagens que: "Ideologiasservem comoum meio importante paraestabelecer e manterrelações de poder desiguaisatravés do discurso(...). Contudo, ideologias funcionam também como um meio de transformar mais ou menos radicalmente as relações de poder" (Reisigl; Wodak, 2009: 88.)

São essas "aberturas ao diálogo" da ADC, tanto para fora quanto para dentro, que me deixam utilizá-la com tranquilidade, apesar das críticas que levo comigo. Há no projeto da $\mathrm{ADC}$, e isso a vincula indubitavelmente à crítica ao racionalismo científico, espaço para autocrítica e para posicionamentos díspares, como demonstra a forte crítica de Paul Chilton, acima mencionada, incluída em coletânea de ADC organizada por ele juntamente com Wodak (2005), na qual constam textos de vários outros expoentes da ADC. Não se trata de um caso isolado a inclusão de autocrítica em coletâneas de textos em ADC, ela é mesmo muitas vezes incentivada, como o faz Michael Billig, em alerta sobre o que chama de retórica da crítica: "Como será sugerido, se os analistas críticos falham em ser auto-reflexivos, então a própria crítica pode ser comprometida, na medida em que os limites críticos da crítica são ignorados e escondidos." (Billig: 20033: 37). O autor continua:

Acima de tudo, há uma necessidade de incentivar os jovens acadêmicos, especialmente aqueles sem posições estabelecidas, a criticar a linguagem e retórica dos escritores críticos estabelecidos (...). Os resultados podem não ser confortáveis para os especialistas críticos; e nem devem mesmo ser, se é para a atividade de crítica social continuar no futuro (Billig, 2003: 45)

É então a própria ADC que me leva a crer ser essencial o posicionamento crítico frente a essa metodologia, mesmo que a considere adequada e pertinente à minha pesquisa.

\section{Considerações finais}


Para concluir, sobre o hibridismo metodológico proposto cabe ainda uma explicação ao leitor mais atento de que, embora cheio de idas e vindas entre as metodologias utilizadas, há em minhas interpretações uma distinção importante entre narrativa e discurso, diferenciação reclamada por narrativistas, como, por exemplo, Hayden White (1987) e fundamental para ADC. Embora na própria construção de meu texto, reconheça que em alguns momentos a aproximação que opero dificulta a distinção, esta existe e deve ser destacada. Toda narrativa é também uma manifestação discursiva, são textos e, como tais, materializações de discursos. É neste sentido, e somente neste sentido, que falo em narrativas discursivas ou em discursos narrativos, o que me permite, em certa medida, transitar entre interpretações de narrativas e de discurso.

Contudo, dentro da concepção de discurso adotada - como parte da estrutura abstrata de organização das relações sociais, operada por meio da linguagem -e dentro da ideia de narrativa acolhida - como gênero textual que permite a organização humana do tempo -, discurso se aproxima muito do que os/as historiadores/as (e também os/as analistas críticos/as de discurso) entendemos como representações sociais, enquanto que narrativas se enquadrariam muito bem nas práticas sociais, assim definidas tanto por historiadores/as da cultura, quanto por analistas críticos/as do discurso.

As metodologias escolhidas, em maior ou menor grau, em muitas ou em algumas acepções, são, todas elas, claramente promíscuas, como define Lynn Abrams o uso da história oral como metodologia:"'Os historiadoresque trabalham com história oralaprenderam a serpromíscuosno uso deperspectivas teóricasetomar emprestartécnicas analíticasda literaturaelinguística, psicologia e antropologia,estudosde folcloreeasartes performativas, para citar apenas algumass" (Abrams, 2010: 3).

Acredito que assim também posso entender os argumentos de Gilbert Weiss e Ruth Wodak, no caso da ADC, quando afirmam que "gostaríamos de salientar que aADCnunca foie nuncatentouserou forneceruma teoriaúnica ouespecífica, e uma metodologia específicanão é característicada pesquisa em ADC" (Weiss; Wodak, 2003: 12).

Assim também entendo Mieke Bal, no caso do uso da análise de narrativa como interpretação de cultura, quando propõe que "narrative is a cultural attitude, hence, narratology a perspective on culture" (Bal, 1999: 21).

O "hibridismo metodológico" que proponho é, pois, intrínseco às metodologias que escolhi para trabalhar, mas exige um esforço intelectual e emocional bastante grande. Contudo, além do risco de ver o esforço interdisciplinar ser "julgado" como amadorismo ou ecletismo, 
as possibilidades descobertas podem trazer momentos de conforto. Sobre o "risco" do ecletismo concordo com a tranquilidade com que Lister e Wells propõem que

Os Estudos Culturais são não só metodologicamente ecléticos, mas também abertos e experimentais nos caminhos que moldam seus objetos de estudo(...). Pragmaticamente, suas conquistas têm que ser julgadas em termos de coerência e das contribuições à interpretação que ele dá aos objetos. O seu rigor metodológico está na maneira responsável que o pesquisador utiliza os recursos intelectuais que toma emprestados e aplica (Lister; Wells, 2001: 63-64)

Como creio que as reflexões metodológicas propostas se encaixam sobretudo dentro do campo transdisciplinar dos Estudos Culturais, creio também que tais reflexões devem ser julgadas por sua coerência e pelas perspectivas e novos horizontes que elas possam proporcionar à pesquisa qualitativa interdisciplinar.

Sobre as reflexões teóricas acerca da concepção de ideologia adotada pela ADC, cabe talvez responder aqui a pergunta: se o objetivo da ADC não for "desvelar" discursos ideológicos e conscientizar por meio da análise científica sistemática pessoas comuns sobre as armadilhas do senso comum, para que então serve a interpretação alcançada pela ADC? Margaret Jäger propõe, de forma mais sensível, que a ADC pode "contribuir para a sensibilizaçãodos sujeitos envolvidoseenredados no discurso" (Jäger, 1996: 40), auxiliando assim nos movimentos de emancipação do sujeito. Embora concorde com Jäger e veja uma grande diferença entre "desvelar para" e "sensibilizar os", creio, talvez complementarmente, que a ADC serve também para desmontar, interpretar e compreender as ideologias fundadas na dominação, como forma de instrumentalizar as ideologias de libertação para a constante e ininterrupta luta pela hegemonia. Mais do que um projeto científico de entendimento da verdade, acho que a contribuição maior da ADC para o mundo já é, e pode ser ainda mais, a instrumentalização política para a ascensão de uma hegemonia da solidariedade e da comunhão.

Recebido em: 13/10/2014 Aprovado em: 05/11/2014 glaucofeijo@yahoo.com.br

\section{Referências Bibliográficas}

Abrams, L. Oral history theory. London: Routledge, 2010.

Alberti, V. Narrativas na história oral. In: Anais do Simpósio Nacional de História. João Pessoa: ANPUH-PB, 2003. 
Bal, M. Close Reading today. From Narratology to cultural analysis. In: Grünzweig,W.; Solbach, A. (orgs.) Grenzüberschreitungen: Narratologie im Kontext, Tübingen: Gunter Narr, 1999.

Bamberg, M. Identity and Narration. In: Hühn, P. et al.(orgs.) Handbook of narratology. Berlin; New York: Walter de Gruyter, 2009.

Billig, M. Critical Discourse Analysis and the rhetoric of critique. In: Weiss, G.; Wodak, R.(orgs.) Theory and Interdisciplinarity in Critical Discourse Analysis, Basingstoke: Palgrave Macmillan, 2003.

Bobbio, N. A era dos direitos. Rio de Janeiro: Campus, 1992.

Boia, L. Pour une histoire de l'imaginaire. Paris: Les Belles Lettres, 1998.

Castoriadis, C. A instituição imaginária da sociedade. Rio de Janeiro: Paz e Terra, 1997.

Chilton, P. A. Missing links in mainstream Critical Discourse Analysis. In: Chilton, P.A.; Wodak, R. (orgs.) A new agenda in (critical) discourse analysis. Theory, methodology and interdiscilinarity. Amsterdam: John Benjamins Pub. Co., 2005.

Chilton, P.A.; Wodak, R. (orgs.) A new agenda in (critical) discourse analysis. Theory, methodology and interdiscilinarity. Amsterdam: John Benjamins Pub. Co., 2005.

Chouliaraki, L.; Fairclough, N.Discourse in late modernity. Edinburgh: Edinburgh University Press, 2009.

Fairclough, N. A dialectical-relational approach to critical discourse analysis in social research.In: Wodak, R.; Meyer, M. (orgs) Methods of critical discourse analysis, London: Sage, 2009.

Fairclough, N. Analysing discourse. London: Routledge, 2003.

Gouveia, C.A. Critical Discourse Analysis and the developement of the new science. In: Weiss, G.; Wodak, R.(orgs.)Theory and Interdisciplinarity in Critical Discourse Analysis, Basingstoke: Palgrave Macmillan, 2003.

Gramsci, A. Cuadernos de la cárcel. Tomo 2, Cuaderno 4 (XIII). México: Ediciones Era, 2001

Gruppi, L. Il concetto di egemonia in Gramsci. Roma: Editori Riuniti-Istituto Gramsci, 1972.

Hall, S. Significação, representação, ideologia: Althusser e os debates pós-estruturalistas.In: $D a$ Diáspora. Identidades e mediações culturais. Belo Horizonte: Editora UFMG, 2003.

Hunt, L. A invenção dos direitos humanos. São Paulo: Companhia da Letras, 2009.

Jäger, M. Fatale Effekte. Die Kritik am Patriarchat im Einwanderungsdiskurs. Duisburg: DISS, 1996.

Lister, M.; Wells, L. Seeing beyond belief: Cultural Studies as an approach to analysing the visual. In: van Leeuwen, T.; Jewitt, C. (orgs) Handbook of visual analysis, London: Sage, 2001.

Motta, L. G. Análise crítica da narrativa. Brasília: Editora da UnB, 2013.

Neumman, B et. al. (orgs.) Narrative and identity. Theoretical approaches and critical analyses. Trier: Wiss. Verlag, 2008.

Nünning, A.; Nünning, V. Neue Ansätze in der Erzähltheorie. Trier: Wissenschaftlicher Verlag, 2009.

Portelli, H. Gramsci e o bloco historico. Rio de janeiro: Paz e Terra, 1990. 
Ramalho, V.; Resende, V. Análise de Discurso (para a) Crítica: o texto como material de pesquisa. Campinas: Pontes, 2011.

Reisigl, M.; Wodak, R. The discourse-historical approach (DHA), In: Wodak, R.; Meyer, M. (orgs) Methods of critical discourse analysis, London: Sage, 2009.

Resende, V. Análise de discurso crítica e realismo crítico. Implicações interdisciplinares. Campinas: Pontes, 2009.

Resende, V.; Ramalho; V. Análise de discurso crítica. São Paulo: Contexto, 2009.

Ricouer, P. Tempo e narrativa. Campinas: Papirus, 1994.

Santos, B. de Sousa. Um discurso sobre as ciências. São Paulo: Cortez, 2011.

Thompson, E. P. A miséria da teoria ou um planetário de erros. Rio de Janeiro: Zahar, 1981.

Thompson, J. B. Ideoloy and mordern culture: critical social theory in the era of mass communication. Stanford, Calif. : Stanford Univ. Press, 1990.

Van Leeuwen, T. Three models of interdisciplinarity.In: Chilton, P.A.; Wodak, R. (orgs.)A new agenda in (critical) discourse analysis. Theory, methodology and interdiscilinarity. Amsterdam: John Benjamins Pub. Co., 2005.

Van Leeuwen, T. Discouse and practice. New tools for critical discourse analysis. New York: University Oxford Press, 2008.

Weiss, G.; Wodak, R.(orgs.) Theory and Interdisciplinarity in Critical Discourse Analysis, Basingstoke: Palgrave Macmillan, 2003..

Whyte, $\mathrm{H}$. The value of narratvity in the representation of reality. In: The content of the form. Narrative, discourse and historical representation. London; Baltimore: Johns Hopkins University Press, 1987.

Wodak, R. Do que trata a ADC. Um resumo da sua história, conceitos importantes e desenvolvimentos. In:Linguagem em (Dis)curso, vol 4, 2004,p. 223-243. 